\title{
Effect of adding postoperative noninvasive ventilation to usual care to prevent pulmonary complications in patients undergoing coronary artery bypass grafting: A randomized controlled trial
}

\author{
Emad Al Jaaly, MD, MRCS, ${ }^{a}$ Francesca Fiorentino, PhD, MSc, BSc, ${ }^{b}$ Barnaby C. Reeves, MSc, DPhil, ${ }^{\mathrm{c}}$ \\ Philip W. Ind, MA, FRCP, ${ }^{\mathrm{d}}$ Gianni D. Angelini, MD, MCh, FRCS, FETCS, FMedSci, ${ }^{\mathrm{b}}$ Scott Kemp, MBBS, \\ BSc, FRCA, ${ }^{\mathrm{e}}$ and Robert J. Shiner, MRCS, FRCP ${ }^{\mathrm{d}}$
}

Objective: We compared the efficacy of noninvasive ventilation with bilevel positive airway pressure added to usual care versus usual care alone in patients undergoing coronary artery bypass grafting.

Methods: We performed a 2-group, parallel, randomized controlled trial. The primary outcome was time until
fit for discharge. Secondary outcomes were partial pressure of carbon dioxide, forced expiratory volume in 1 sec-
ond, atelectasis, adverse events, duration of intensive care stay, and actual postoperative stay.

Results: A total of 129 patients were randomly allocated to bilevel positive airway pressure (66) or usual care (63). Three patients allocated to bilevel positive airway pressure withdrew. The median duration of bilevel positive airway pressure was 16 hours (interquartile range, 11-19). The median duration of hospital stay until fit for discharge was 5 days for the bilevel positive airway pressure group (interquartile range, 4-6) and 6 days for the usual care group (interquartile range, 5-7; hazard ratio, 1.68; 95\% confidence interval, $1.08-2.31 ; P=.019)$. There was no significant difference in duration of intensive care, actual postoperative stay, and mean percentage of predicted forced expiratory volume in 1 second on day 3 . Mean partial pressure of carbon dioxide was significantly reduced 1 hour after bilevel positive airway pressure application, but there was no overall difference between the groups up to 24 hours. Basal atelectasis occurred in 15 patients (24\%) in the usual care group and 2 patients (3\%) in the bilevel positive airway pressure group. Overall, $30 \%$ of patients in the bilevel positive airway pressure group experienced an adverse event compared with $59 \%$ in the usual care group.

Conclusions: Among patients undergoing elective coronary artery bypass grafting, the use of bilevel positive airway pressure at extubation reduced the recovery time. Supported by trained staff, more than $75 \%$ of all patients allocated to bilevel positive airway pressure tolerated it for more than 10 hours. (J Thorac Cardiovasc Surg 2013;146:912-8)

From Cardiothoracic Surgery, ${ }^{a}$ Hammersmith Hospital, Imperial College NHS Trust, London, United Kingdom; Cardiothoracic Surgery, ${ }^{\mathrm{b}}$ National Heart and Lung Institute, Hammersmith Hospital, Imperial College, London, United Kingdom; Clinical Trials and Evaluation Unit, ${ }^{\mathrm{c}}$ University of Bristol, Bristol Royal Infirmary, Bristol, United Kingdom; Respiratory Department, ${ }^{\mathrm{d}}$ National Heart and Lung Institute, Hammersmith Hospital, Imperial College, London, United Kingdom; and Department of Anaesthesia, ${ }^{\mathrm{e}}$ Hammersmith Hospital, Imperial College NHS Trust, London, United Kingdom.

The equipment for the BLPAP used in the study was donated by Philips Respironics (Chichester, UK). The study was partly supported by the National Institute for Health Research Bristol Cardiovascular Biomedical Research Unit. Neither Philips Healthcare nor the National Institute for Health Research had any role in the design, conduct, analysis, or reporting of the trial. The trial was sponsored by Imperial College London. The trial was designed, conducted, analyzed, and interpreted independently of the sponsor. The authors had full access to the data and are responsible for submitting the publication. The views expressed are those of the authors and not necessarily those of the NHS, the National Institute of Health Research, or the Department of Health.

Disclosures: Authors have nothing to disclose with regard to commercial support.

Received for publication Sept 28, 2012; revisions received Feb 19, 2013; accepted for publication March 6, 2013; available ahead of print April 15, 2013.

Address for reprints: Robert J. Shiner, MRCS, FRCP, NHLI, Airway Disease, N204, Hammersmith Hospital, Imperial College London, Du Cane Rd, London, W12 0NN, United Kingdom (E-mail: r.shiner@imperial.ac.uk).

0022-5223/\$36.00

Copyright (C) 2013 by The American Association for Thoracic Surgery

http://dx.doi.org/10.1016/j.jtcvs.2013.03.014
Supplemental material is available online.

The long-term benefits of coronary artery bypass grafting (CABG) for patients with multivessel coronary heart disease are established but must be weighed against possible shortterm iatrogenic harm. CABG interferes with pulmonary function, with basal atelectasis detected in up to $94 \%$ of patients in the first 48 postoperative hours. ${ }^{1,2}$ Basal atelectasis is associated with decreased lung compliance, a higher incidence of infection, and prolonged hospital stay. ${ }^{2,3}$

Postoperative physiotherapy, often incorporating incentive spirometry, is now usual care after CABG. The term "enhanced recovery" comprises various evidence-based components of perioperative care and aims to expedite recovery after surgery. In recent years, the concept of enhanced recovery ${ }^{4}$ has become more accepted. There is interest in the role of noninvasive ventilation (NIV) after cardiac surgery given the benefits of NIV in respiratory failure in other clinical settings, for example, exacerbations 


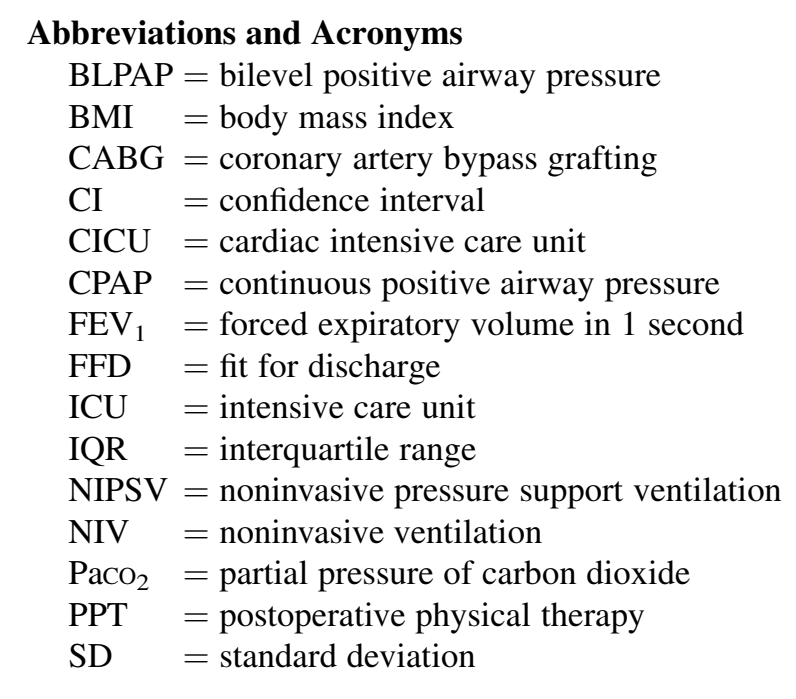

of chronic obstructive pulmonary disease, ${ }^{5}$ cardiogenic pulmonary edema, and pneumonia.

There is some evidence that NIV after extubation may be beneficial. For example, preventive use of continuous positive airway pressure (CPAP) or bilevel positive airway pressure (BLPAP) can reduce postoperative lung restriction and venous admixture. ${ }^{6}$ BLPAP developed from CPAP in the 1990s. It matches the respiratory cycle by generating 2 different positive airway pressure levels. ${ }^{7}$ BLPAP can improve gas exchange and oxygenation, ${ }^{8-10}$ even in the absence of hypercapnea, and BLPAP was significantly more effective than CPAP in treating postoperative atelectasis after $\mathrm{CABG}$ in a randomized comparison in 150 patients. ${ }^{11}$ Another recent trial of BLPAP after CABG showed reductions in atelectasis but not in other clinical measurements. ${ }^{12}$ However, these trials did not optimize BLPAP. It has been suggested that intermittent postoperative NIV for up to 3 hours should be part of standard clinical practice despite the paucity of evidence. ${ }^{13}$ There is no relevant systematic review of NIV after cardiac surgery. One review of incentive spirometry to prevent postoperative pulmonary complications after CABG identified trials that confounded incentive spirometry with co-interventions, including NIV. ${ }^{14}$

We hypothesized that BLPAP after CABG would reduce postoperative stay by improving lung physiology and gas exchange and reducing basal atelectasis. We conducted a randomized controlled trial to compare BLPAP added to usual care with usual care alone in patients undergoing isolated first-time CABG.

\section{MATERIALS AND METHODS \\ Study Design}

The study was a single-center, 2-group, parallel, pragmatic, randomized controlled trial. An independent statistician generated the random allocation sequence by computer in blocks (ratio 1:1). E.A.J. enrolled and randomized participants, usually immediately before the operation, by looking up the next numbered allocation in the sequence. Participants' random allocations were not concealed during recruitment. The allocation was communicated to cardiac intensive care unit (CICU) staff during the operation so the BLPAP equipment could be prepared if required. The trial was registered as ISRCTN85570732.

This study was approved by the Hammersmith and Queen Charlotte's \& Chelsea research ethics committee (reference number 07/Q0406/79) on April 9, 2007. Further approval was obtained from the research and development department of the Imperial College Healthcare NHS Trust. This research complies with the Helsinki Declaration.

\section{Trial Population}

The reference population was patients referred to the Hammersmith Hospital for isolated first-time CABG using cardiopulmonary bypass and mild hypothermia $\left(32^{\circ} \mathrm{C}\right)$. Patients requiring emergency surgery, with a history of renal impairment (creatinine $>200 \mu \mathrm{mol} / \mathrm{L}$ ), with hepatic or hematologic disease, with poor left ventricular function, or with chronic infection (eg, tuberculosis, chronic bronchitis) were ineligible.

\section{Intervention and Comparator}

Immediately after surgery, all participants were mechanically ventilated using standard method (Servo I and Servo 300; Maquet Getinge Group, Wayne, NJ) ventilators providing a tidal volume of 7 to $10 \mathrm{~mL} / \mathrm{kg}$. Immediately after weaning and extubation, participants received BLPAP treatment in addition to usual care (BLPAP group) or usual care alone, as allocated.

We aimed to maximize the duration of BLPAP during the first 24 hours after extubation. BLPAP was administered through an oronasal mask, which was worn continuously except when a participant needed to eat or drink. BLPAP was discontinued after 24 hours or earlier if it was not tolerated by the participant. Inspiratory and expiratory positive airway pressure settings were predetermined and stratified by body mass index (BMI) (ie, $-12 \mathrm{~cm} \mathrm{H}_{2} \mathrm{O}$ and $+5 \mathrm{~cm} \mathrm{H}_{2} \mathrm{O}$, respectively, if $\mathrm{BMI}<30$, and $17 \mathrm{~cm} \mathrm{H}_{2} \mathrm{O}$ and $10 \mathrm{~cm} \mathrm{H}_{2} \mathrm{O}$ if $\mathrm{BMI} \geq 30$ ). BLPAP was performed by CICU staff who received training on 12 occasions before the study started.

Usual care alone included chest physiotherapy, nebulized bronchodilators ( $2.5 \mathrm{mg}$ salbutamol every 6 hours), coughing exercises, nebulized saline ( $5 \mathrm{~mL}$ every 6 hours), mobilization, and incentive spirometry, overseen by physiotherapists twice per day for the first 2 to 3 days after surgery.

\section{Outcomes}

The primary outcome was days until fit for discharge (FFD), measured from the operation date. A judgment of FFD required (1) normal blood pressure, heart rate, temperature, and oxygen saturation on air; (2) bowels open; (3) back to preoperative mobility/reasonable mobility; and (4) satisfactory wound healing. FFD was chosen to reflect the overall speed of recovery. It was considered an important measure for patients, clinicians, and health services that would be unaffected by nonmedical factors. FFD and serious complications (postoperative morbid events considered to lengthen expected hospital stay) were judged by the clinical team, who were not blinded to allocation.

Secondary outcomes included arterial partial pressure of carbon dioxide $\left(\mathrm{PaCO}_{2}\right)$ and forced expiratory volume in 1 second $\left(\mathrm{FEV}_{1}\right)$, atelectasis scored clinically and radiologically, complications, intensive care unit (ICU) length of stay, and time until actual discharge. $\mathrm{PaCO}_{2}$ was measured immediately after extubation and at 1,12 , and 24 hours later. $\mathrm{FEV}_{1}$ was measured on days 1,2, and 3 after surgery. However, because of sternotomy wound pain, acceptable measurements (European Respiratory Society criteria) were achieved in only a minority of patients. ${ }^{15}$

Atelectasis was assessed on day 1 after surgery by the senior clinical team, not involved in the trial but responsible for the patients' care, as present or absent on the basis of standard clinical and chest $\mathrm{x}$-ray criteria. Radiologists reporting on $\mathrm{x}$-rays were blinded to allocation. 
Postoperative complications other than atelectasis also were recorded. Serious complications were itemized. Other complications were recorded as free text and classified subsequently.

\section{Statistical Analysis}

The target sample size was 126 participants. For time until FFD, the trial had $90 \%$ power at a $5 \%$ 2-tailed significance level to detect a standardized difference of 0.6 standard deviations (SDs) or more in $\log$ length of stay based on geometric mean times until FFD of 10 and 8.5 days (Online Data Supplement). For $\mathrm{PaCO}_{2}$ and $\mathrm{FEV}_{1}$, we estimated (retrospectively) that the trial had $90 \%$ power at a $5 \%$ 2-tailed significance level to detect a standardized difference of $0.38 \mathrm{SD}$ or more.

Primary analyses were by intention to treat. The analysis plan (Online Data Supplement) specified that time until FFD, CICU stay, and actual postoperative stay should be analyzed as time-to-event data. The analysis of repeated $\mathrm{PaCO}_{2}$ used a mixed regression model to take into account the repeated measurements and to adjust for $\mathrm{PaCO}_{2}$ at the time of extubation. Mean $\mathrm{PaCO}_{2}$ levels also were analyzed 1 hour after starting NIV to test the effectiveness of administration of BLPAP. Only the day $3 \mathrm{FEV}_{1}$ measurement was analyzed, using multivariable regression to adjust for the baseline measurement.

Continuously scaled outcomes are described as means \pm SD for each group. Treatment effects (mean differences between groups and $95 \%$ confidence intervals [CIs]) were estimated from the regression models. Binary/categoric outcomes are presented as frequencies. Statistical analyses were performed using STATA version 11 (StataCorp LP, College Station, Tex).

\section{RESULTS \\ Study Population}

Of 134 patients considered for the study between February 2008 and February 2011, the trial recruited 129 participants; 66 were randomly allocated to BLPAP, and 63 were randomly allocated to usual care (Figure 1). Three participants withdrew from the BLPAP group because they could not tolerate the mask, giving a total of 126 patients who all received their allocated management. Six participants in the usual care group required ventilatory support and received CPAP. Baseline characteristics, preoperative comorbidities, operation details, and baseline respiratory measurements were balanced (Tables 1 and 2). Two patients died; 1 in the BLPAP group died on day 2 , and 1 in the usual care group died on day 5 .

\section{Duration of Ventilation}

The median intubation time was 6 hours for both groups (interquartile range [IQR], 5-8 and 4-10, respectively). The median time achieved on BLPAP in the BLPAP group was 16 hours (IQR, 11-19; range, 0-22).

\section{Primary Outcome}

Time until fit for discharge. Follow-up for the 2 patients who died in hospital was censored at the time of death. Median times until FFD were 6 days (IQR, 5-7) and 5 days (IQR, 4-6) for the control and treatment groups, respectively, generating a hazard ratio of 1.68 (95\% CI, $1.17-2.43 ; P=.005)$. Figure $2, A$ shows the cumulative proportion of participants judged FFD with increasing

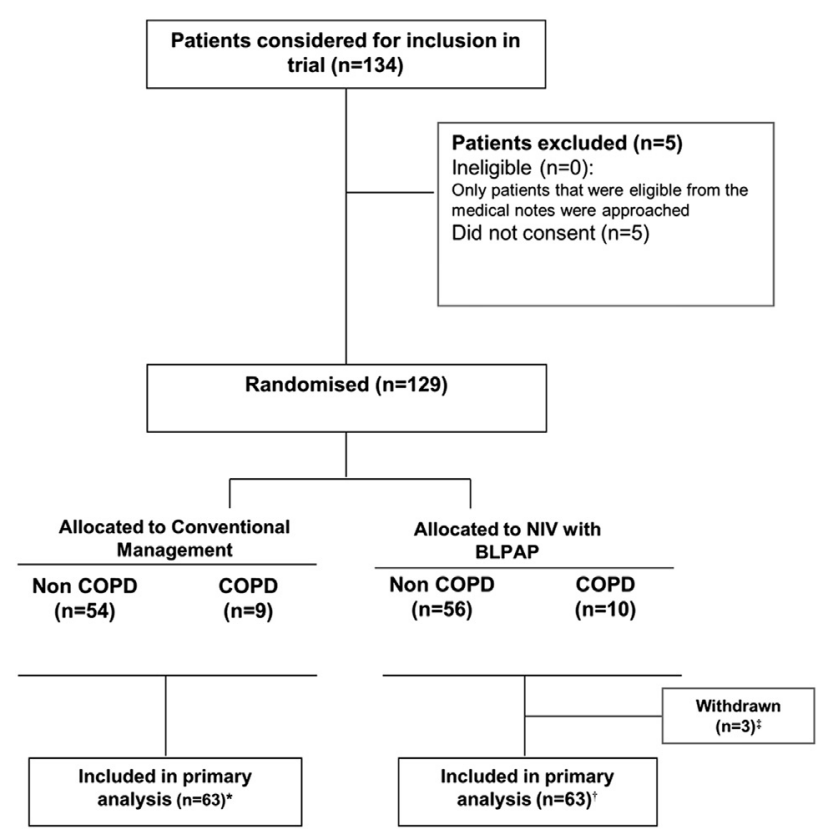

FIGURE 1. Patient flow in the trial. *All received conventional management. For 6 patients requiring noninvasive ventilation support, this included continuous positive air pressure. $\dagger$ All received BLPAP but for varying duration (median time on BLPAP $=16$ hours [interquartile range, 11-19]). $\ddagger$ Three participants asked to be withdrawn because they could not tolerate BLPAP (duration of BLPAP $=0$ hours). BLPAP, Bilevel positive airway pressure; $N I V$, noninvasive ventilation; $C O P D$, chronic obstructive pulmonary disease.

time, with more patients in the BLPAP group than in the usual care group judged FFD from day 3 onward.

\section{Secondary Outcomes}

Partial pressure of carbon dioxide. Mean $\mathrm{PaCO}_{2}$ levels at 1,12 , and 24 hours are shown in Table $3 . \mathrm{PaCO}_{2}$ at 1 hour was statistically significantly different (BLPAP vs usual care, $-0.41 \mathrm{kPA} ; 95 \% \mathrm{CI},-0.73$ to $-0.09 ; P=.011$ ) when adjusted for $\mathrm{PaCO}_{2}$ at the time of extubation, providing evidence that BLPAP was administered efficaciously in the study. The mean difference in $\mathrm{PaCO}_{2}$ over 24 hours (BLPAP vs usual care) was $-0.06 \mathrm{kPA}(95 \% \mathrm{CI},-0.25$ to 0.13 ; $P=.54$ ) when adjusted for $\mathrm{PaCO}_{2}$ at the time of extubation. Forced expiratory volume in 1 second. Mean FEV levels at days 1, 2, and 3 are shown in Table 3. Absolute values were markedly reduced in both groups postoperatively because of wound pain and difficulty performing forced maneuvers. The mean difference in percent predicted $\mathrm{FEV}_{1}$ at day 3 (BLPAP vs usual care) was $4 \%$ ( $95 \% \mathrm{CI},-3$ to $12 ; P=.24$ ) when including preoperative percent predicted $\mathrm{FEV}_{1}$ as a covariate.

Intensive care unit length of stay. No patient died before discharge from the ICU. Median lengths of ICU stay were 24 hours (IQR, 18-42) and 20 hours (IQR, 17-40) for the usual care and BLPAP groups, respectively. The hazard ratio for BLPAP versus usual care was $1.20(95 \% \mathrm{CI}$, $0.84-1.71 ; P=.306)$. 
TABLE 1. Patients' characteristics and operation details

\begin{tabular}{|c|c|c|c|c|c|}
\hline \multirow{2}{*}{ Patient demographics } & & \multicolumn{2}{|c|}{ BLPAP } & \multicolumn{2}{|c|}{ Usual care } \\
\hline & & Iean & SD & Mean & SD \\
\hline \multirow{5}{*}{$\begin{array}{l}\text { Age }(\mathrm{y}) \\
\text { Height }(\mathrm{cm}) \\
\text { Weight }(\mathrm{kg}) \\
\text { BMI }\left(\mathrm{kg} / \mathrm{m}^{2}\right) \\
\end{array}$} & & 65.76 & 10.77 & 69.41 & 8.86 \\
\hline & & 69.17 & 7.89 & 168.03 & 7.69 \\
\hline & & 31.82 & 18.29 & 80.39 & 14.68 \\
\hline & & 28.47 & 5.28 & 28.45 & 4.57 \\
\hline & & $\begin{array}{c}\text { No. of } \\
\text { patients }\end{array}$ & $(\%)$ & $\begin{array}{c}\text { No. of } \\
\text { patients }\end{array}$ & $(\%)$ \\
\hline \multicolumn{6}{|l|}{ NYHA class } \\
\hline 0 & & 5 & 7.9 & 5 & 8 \\
\hline 1 & & 17 & 27 & 16 & 25.8 \\
\hline 2 & & 29 & 46 & 34 & 54.8 \\
\hline 3 & & 10 & 15.9 & 6 & 9.7 \\
\hline 4 & & 2 & 3.2 & 1 & 1.6 \\
\hline \multicolumn{6}{|l|}{ Left ventricular function } \\
\hline Good $(>50 \%)$ & & 53 & 84.1 & 52 & 82.5 \\
\hline Moderate $(30 \%-50 \%)$ & & 10 & 15.9 & 11 & 17.5 \\
\hline \multicolumn{6}{|l|}{ Comorbidities } \\
\hline \multicolumn{6}{|l|}{ Respiratory } \\
\hline COPD* & & 10 & 15.9 & 9 & 14.3 \\
\hline Smoker/ex-smoker & & 29 & 46 & 30 & 47.6 \\
\hline Other & & 3 & 4.8 & 1 & 1.6 \\
\hline \multicolumn{6}{|l|}{ Cardiovascular } \\
\hline Hypertension & & 58 & 92.1 & 54 & 85.7 \\
\hline Hypercholesterolemia & & 53 & 84.1 & 56 & 88.9 \\
\hline Other & & 4 & 6.4 & 3 & 4.8 \\
\hline \multicolumn{6}{|l|}{ Systemic } \\
\hline Diabetes mellitus & & 19 & 30.2 & 15 & 23.8 \\
\hline Other & & 1 & 1.6 & 1 & 1.6 \\
\hline \multicolumn{6}{|l|}{ Other } \\
\hline Family history & & 16 & 15.9 & 15 & 14.3 \\
\hline Other & & 1 & 1.6 & 7 & 11.1 \\
\hline None & & 0 & 0 & 1 & 1.6 \\
\hline Operation details & Median & & $\mathrm{QR}$ & Median & IQR \\
\hline Bypass (min) & 71 & 63.5 & -93.5 & 80 & $60-92$ \\
\hline Crossclamp (min) & 38 & & -48 & 46 & $33-54$ \\
\hline Intubation $(\mathrm{h})$ & 6 & & -10 & 6 & $5-8$ \\
\hline
\end{tabular}

$B L P A P$, Bilevel positive airway pressure; $S D$, standard deviation; $B M I$, body mass index; $N Y H A$, New York Heart Association; $C O P D$, chronic obstructive pulmonary disease; $I Q R$, interquartile range. ${ }^{*}$ Preoperative $\mathrm{COPD}$ was defined as $\mathrm{FEV}_{1} \%$ $\left(\mathrm{FEV}_{1} / \mathrm{FVC}\right.$ ratio $)<70 \%$.

Time until discharge. By censoring follow-up for the 2 patients who died, median lengths of hospital stay were 6 days (IQR, 5-8) for both groups. The hazard ratio for BLPAP versus usual care was $1.12(95 \% \mathrm{CI}, 0.78-1.60 ; P=.552)$.

Postoperative complications. Table 4 describes complications. One or more respiratory complications occurred in 23 patients $(37 \%)$ and 9 patients $(14 \%)$ in the usual care and BLPAP groups, respectively. As hypothesized, basal atelectasis, as judged clinically, occurred less often in the BLPAP group ( 2 patients, $3 \%$ ) than in the usual care group (15 patients, $24 \%$ ). Nonrespiratory complications occurred with similar frequency in both groups.
TABLE 2. Baseline respiratory measurements by group

\begin{tabular}{|c|c|c|c|c|}
\hline \multirow[b]{2}{*}{ Variable } & \multicolumn{2}{|c|}{ BLPAP } & \multicolumn{2}{|c|}{ Usual care } \\
\hline & Mean & SD & Mean & SD \\
\hline$\%$ predicted $\mathrm{FEV}_{1}(\mathrm{~L})$ & 0.84 & 0.19 & 0.88 & 0.2 \\
\hline FVC & 3.26 & 0.89 & 3.26 & 0.9 \\
\hline $\mathrm{PaCO}_{2}(\mathrm{kPA})$ & 5.38 & 0.70 & 5.14 & 0.7 \\
\hline $\mathrm{PaO}_{2}$ & 29.21 & 13.30 & 33.17 & 13.72 \\
\hline Inspiratory mouth pressure* & -84.28 & 24.08 & -80.81 & 25.8 \\
\hline Expiratory mouth pressure* & 136.87 & 47.65 & 128.59 & 35.5 \\
\hline
\end{tabular}

BLPAP, Bilevel positive airway pressure; $S D$, standard deviation; $F E V_{l}$, forced expiratory volume in 1 second; $\mathrm{FVC}$, forced vital capacity; $\mathrm{Paco}_{2}$, partial pressure of carbon dioxide; $\mathrm{PaO}_{2}$, partial pressure of oxygen. *Inspiratory and expiratory mouth pressure measurements were missing for approximately $33 \%$ of the patients because they had their lung function tests performed at the referring hospital before their admission to the Hammersmith Hospital. In this case, lung function tests were not repeated when patients were admitted to Hammersmith Hospital.

\section{DISCUSSION}

There are 3 main findings of this trial. First, we successfully implemented BLPAP. Among participants allocated to BLPAP, the median duration of BLPAP was 16 hours and $75 \%$ managed more than 10 hours. Only 3 participants failed to tolerate BLPAP. Implementation of BLPAP by the CICU staff was accomplished with limited training. This finding is important because continuous NIV for more than a few hours at a time is typically considered unfeasible, and for this reason, it is often implemented intermittently. ${ }^{6,13,16,17}$

Second, participants allocated to BLPAP were judged, on average, to be FFD 1 day earlier than participants who had usual care alone. Date of FFD relates strictly to postoperative recovery, whereas date of actual discharge is determined by nonmedical factors (eg, social factors). This is important to patients and health service providers because bed availability is a limiting factor on the capacity of cardiac surgery units in the United Kingdom.

Third, overall respiratory complications and, in particular, atelectasis occurred less often in participants allocated to BLPAP. There were no differences between groups in $\mathrm{FEV}_{1}$ or $\mathrm{PaCO}_{2}$ overall, but $\mathrm{PaCO}_{2}$ did differ between groups 1 hour after extubation, suggesting improved alveolar ventilation due to BLPAP.

\section{Study Strengths and Limitations}

We believe that this is the first trial of preventive BLPAP in addition to usual care versus usual care alone (including incentive spirometry) after CABG. There are several strengths of the trial. The primary outcome, time to medically FFD, was chosen a priori as a global measurement of clinical importance. The trial was designed to be able to detect a clinically important difference in the time until FFD. Our findings should be applicable to publicly funded cardiac surgery settings because the trial was carried out in the UK NHS, there were few exclusion criteria, and the intervention was implemented by the CICU staff responsible for day-to-day care, after limited training. We wrote an 

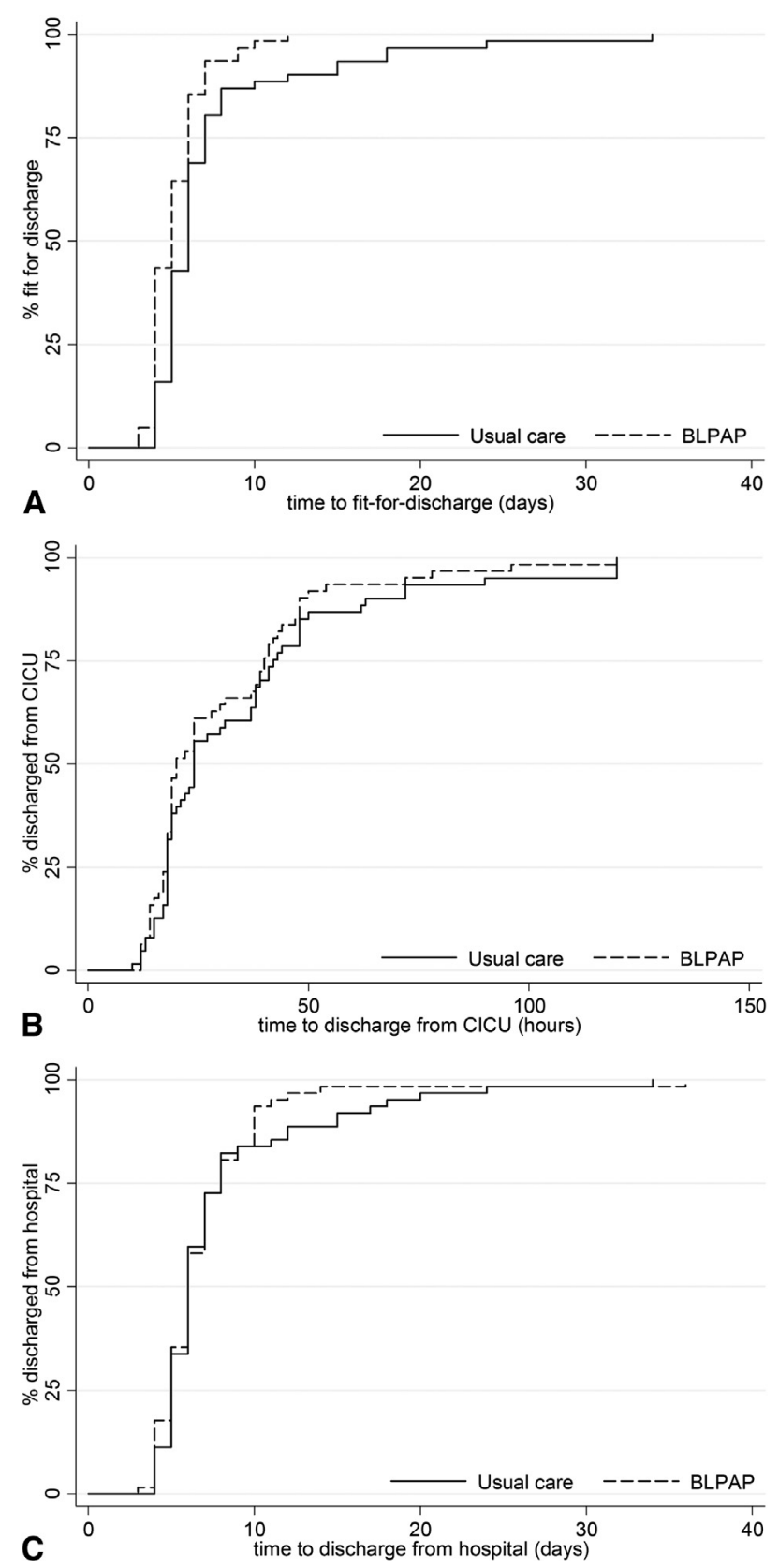

FIGURE 2. A, Proportion of patients fit for discharge. B, Proportion of patients discharged from the CICU. C, Proportion of patients discharged from the hospital. BLPAP, Bilevel positive airway pressure; $C I C U$, cardiac intensive care unit.

analysis plan in advance of unblinding the data to minimize the risk of within-study selective reporting. ${ }^{18,19}$

The trial also had limitations. The randomization sequence was not concealed. However, a high percentage of patients were approached and consented, and the analysis of patients' characteristics, as reported in Table 1, shows balance between the 2 groups in patients' demographics and comorbidities. Allocation was not concealed. It was not feasible to blind the participants, nurses, and research team to allocation; therefore, the primary outcome was at risk of detection bias because the criteria for judging a patient FFD were not completely objective. Ascertainment of complications, including clinical assessment of atelectasis from chest $\mathrm{x}$-rays (reviewed by the cardiothoracic team on ward rounds) and $\mathrm{PaCO}_{2}$ and $\mathrm{FEV}_{1}$ measurements, was expected to be less at risk of bias. The frequency of atelectasis might have been higher if computed tomography scans had been used to make the diagnosis. Unfortunately, $\mathrm{FEV}_{1}$ measurement proved extremely difficult. Measurements were low but consistent with postoperative $\mathrm{FEV}_{1}$ data for patients undergoing $\mathrm{CABG}$ reported by other researchers. ${ }^{20,21}$ Ideally, data for the 3 additional patients randomized to the BLPAP group would have been included (more completely reflecting the intention to treat), but data collection was discontinued when the participants asked to be withdrawn.

\section{RESULTS IN THE CONTEXT OF OTHER LITERATURE}

The previous Cochrane review of incentive spirometry (date of last search December 2004, content assessed as up to date in April 2007) identified 4 relevant trials. ${ }^{14}$ Two trials compared postoperative physical therapy (PPT) with PPT plus incentive spirometry. ${ }^{16,17}$ One trial randomized patients into 3 groups, PPT plus incentive spirometry versus PPT plus NIV using CPAP versus PPT plus NIV with 2 levels of pressure ${ }^{6}$; this latter intervention is similar to BLPAP but not as implemented in our trial. The fourth trial compared PPT plus incentive spirometry versus PPT plus CPAP NIV versus PPT plus NIV with intermittent positive pressure breathing. ${ }^{22}$ Thus, although all of these trials included 1 group with incentive spirometry, the comparator groups varied substantially. We used the same search strategy as the Cochrane review to identify more recent relevant literature.

In one trial, BLPAP was not started until 4 hours after extubation and was applied for only 1 in every 3 hours. ${ }^{6}$ The authors reported the physiologic and lung function outcomes, ICU stay, and proportion developing atelectasis on day 2 but reported changes between preoperative and day 1 measurements, and between day 1 and day 2 measurements, instead of referring both day 1 and day 2 measurements to the baseline. The authors also combined CPAP and BLPAP groups to test the effect of NIV, reporting a statistically significant difference in the mean change in vital capacity and $\mathrm{FEV}_{1}$ from day 1 to day 2 between the combined groups and usual care. However, this finding may arise from selective outcome reporting. ${ }^{18,19}$ The difference in the frequency of postoperative atelectasis $(30 \%$ with usual care vs $15 \%$ with CPAP or BLPAP combined, with blinded assessment) was consistent with our own findings. 
TABLE 3. Partial pressure of carbon dioxide and percentage of predicted forced expiratory volume in 1 second

\begin{tabular}{|c|c|c|c|c|c|c|c|c|c|}
\hline \multicolumn{5}{|c|}{$\mathrm{Paco}_{2}(\mathrm{kPA})^{*}$} & \multicolumn{5}{|c|}{ Percentage of predicted $\mathrm{FEV}_{\mathbf{1}}(\mathrm{L}) \dagger$} \\
\hline \multirow[b]{2}{*}{ Time } & \multicolumn{2}{|c|}{ BLPAP } & \multicolumn{2}{|c|}{ Usual care } & \multirow[b]{2}{*}{ Time } & \multicolumn{2}{|c|}{ BLPAP } & \multicolumn{2}{|c|}{ Usual care } \\
\hline & Mean & SD & Mean & SD & & Mean & SD & Mean & SD \\
\hline Post-extubation & 5.19 & 0.69 & 5.35 & 0.84 & & & & & \\
\hline $1 \mathrm{~h}$ & 5.10 & 0.85 & 5.58 & 1.09 & Day 1 & 0.30 & 0.19 & 0.37 & 0.23 \\
\hline $12 \mathrm{~h}$ & 4.95 & 0.72 & 5.13 & 0.60 & Day 2 & 0.33 & 0.18 & 0.38 & 0.20 \\
\hline $24 \mathrm{~h}$ & 4.91 & 0.60 & 4.95 & 0.53 & Day 3 & 0.43 & 0.22 & 0.40 & 0.20 \\
\hline
\end{tabular}

$\mathrm{PacO}_{2}$, Partial pressure of carbon dioxide; $F E V_{1}$, forced expiratory volume in 1 second; BLPAP, bilevel positive airway pressure; $S D$, standard deviation. * Differences in mean $\mathrm{PaCO}_{2}$ between groups were tested at 1 hour (BLPAP vs usual care, $-0.41 \mathrm{kPA} ; 95 \% \mathrm{CI},-0.73$ to $-0.09 ; P=.011$ ) and across the first 24 hours (BLPAP vs usual care, $0.06 \mathrm{kPA}$; $95 \% \mathrm{CI},-0.25$ to $0.13 ; P=.54)$. $†$ The mean difference in percent predicted $\mathrm{FEV}_{1}$ between groups at day 3 (BLPAP vs usual care) was $4 \%(95 \% \mathrm{CI},-3$ to $12 ; P=.24)$, adjusted for preoperative percent predicted $\mathrm{FEV}_{1}$.

Another trial compared intermittent noninvasive pressure support ventilation (NIPSV, a form of BLPAP, applied 4 times per day) with CPAP in 150 patients with evidence of postoperative radiologic atelectasis. ${ }^{11}$ The patients received CPAP or NIPSV (the maximal pressure delivered was $30 \mathrm{~cm} \mathrm{H}_{2} \mathrm{O}$, positive end-expiratory pressure was $5 \mathrm{~cm} \mathrm{H}_{2} \mathrm{O}$, and the minimal trigger flow was selected) 4 times per day for 30 minutes. Compared with the CPAP group, the NIPSV group had reduced atelectasis according to a radiologic score. However, there were no statistically significant differences in other clinical outcomes (eg, lung function).

TABLE 4. Adverse events

\begin{tabular}{|c|c|c|c|c|}
\hline \multirow[b]{2}{*}{ Adverse event } & \multicolumn{2}{|c|}{ BLPAP } & \multicolumn{2}{|c|}{ Usual care } \\
\hline & $\mathbf{n}$ & $\%$ & $\mathbf{n}$ & $\%$ \\
\hline \multicolumn{5}{|l|}{ Respiratory } \\
\hline CPAP & 4 & 6.4 & 6 & 9.5 \\
\hline Reintubation & 1 & 1.6 & 2 & 3.2 \\
\hline Basal atelectasis & 2 & 3.2 & 15 & 23.8 \\
\hline Bibasal collapse & 0 & 0 & 1 & 1.6 \\
\hline Pneumonia & 0 & 0 & 2 & 3.2 \\
\hline Pleural effusion & 2 & 3.2 & 0 & 0 \\
\hline \multicolumn{5}{|l|}{ Cardiovascular } \\
\hline Atrial fibrillation & 10 & 15.9 & 7 & 11.1 \\
\hline Sinus tachycardia & 0 & 0 & 1 & 1.6 \\
\hline Ventricular tachycardia & 0 & 0 & 1 & 1.6 \\
\hline Cardiac arrest & 1 & 1.6 & 0 & 0 \\
\hline Re-sternotomy & 1 & 1.6 & 3 & 4.8 \\
\hline Ischemia & 0 & 0 & 1 & 1.6 \\
\hline \multicolumn{5}{|l|}{ Neurologic } \\
\hline Confusion & 1 & 1.6 & 2 & 3.17 \\
\hline Transient ischemic attack & 0 & 0 & 1 & 1.6 \\
\hline \multicolumn{5}{|l|}{ Renal } \\
\hline Renal failure & 4 & 6.4 & 7 & 11.1 \\
\hline \multicolumn{5}{|l|}{ Other } \\
\hline Liver infarct & 0 & 0 & 2 & 3.2 \\
\hline Diarrhea & 1 & 1.6 & 0 & 0 \\
\hline Sternal wound infection & 1 & 1.6 & 1 & 1.6 \\
\hline Death & 1 & 1.6 & 1 & 1.6 \\
\hline Other & 0 & 0 & 1 & 1.6 \\
\hline None & 44 & 69.8 & 26 & 41.3 \\
\hline
\end{tabular}

BLPAP, Bilevel positive airway pressure; $C P A P$, continuous positive airway pressure.
A third trial, with 4 groups (25 patients per group), evaluated the pulmonary effects of intermittent NIV with BLPAP (1 hour in every 6 hours), or recruitment maneuver, compared with usual care, after open surgery. ${ }^{12}$ Although this trial was factorial in its design, results were reported for the 4 groups separately. All 3 intervention groups had significantly reduced atelectasis scores (assessed blind to allocation), with the lowest scores in the 2 BLPAP groups. However, no differences were observed in the duration of ICU stay or the length of hospitalization.

\section{INTERPRETATION}

Our finding that BLPAP reduces atelectasis is consistent with 3 previous trials in which assessment of atelectasis was carried out blind to treatment allocation. This finding alone is important, because pulmonary complications and atelectasis are associated with longer duration of hospital stay after other types of thoracic surgery and cardiac surgery. ${ }^{23-25}$ Patients who stay in the hospital longer than expected reduce the availability of beds for patients awaiting elective surgery and decrease the capacity of cardiac surgery centers. The reduction in atelectasis with BLPAP probably explains our finding of a reduction in time until FFD.

Previous trials also found no significant effect of NIV interventions similar to BLPAP for other outcome measures, such as $\mathrm{PaCO}_{2}$ and $\mathrm{FEV}_{1}$. Our failure to observe differences is unlikely to be explained by a lack of power because these outcomes are measured on continuous scales, and, in the case of $\mathrm{PaCO}_{2}$, repeated measurements were analyzed. We also considered that these measures would be less at risk of detection bias and, insomuch as they are intermediary measures of improving respiratory function, more likely to show a benefit. However, practical difficulties in this pragmatic setting, with lack of absolute standardization, for example, with respect to the fraction of inspired oxygen during BLPAP, make them less robust.

In reconciling the findings of the primary and secondary outcomes, one faces a choice between an explanation in terms of bias (which could explain the difference in FFD but not in the frequency of atelectasis) and an explanation 
in terms of the intrinsic variability of postoperative measures of $\mathrm{PaCO}_{2}$ and $\mathrm{FEV}_{1}$. The latter were not robust in the trial setting and are subject to large individual differences arising from variation in patients' pain thresholds, respiratory effort in the early postoperative period, and adherence to instructions for lung function tests. These variations would be expected to contribute noise to measurements of $\mathrm{PaCO}_{2}$ and $\mathrm{FEV}_{1}$.

The consistency of the findings regarding atelectasis across 4 trials strengthens our results and provides a mechanism for the clinical benefit we observed with BLPAP. However, the case for implementation of routine BLPAP after extubation in patients who have undergone $\mathrm{CABG}$ cannot be considered proven, and we are exploring the feasibility of performing a larger multicenter trial with features to reduce the risk of bias. Given the potential resource implications of BLPAP reducing length of stay, it will be important to include an economic evaluation alongside the trial. It may also be possible to further optimize the application of BLPAP.

\section{CONCLUSIONS}

Participants who received NIV with BLPAP in addition to usual care were, on average, judged to be medically FFD (study primary outcome) 1 day earlier than participants who had usual care only. If this reduction in hospital stay could be confirmed in a larger multicenter trial, it would represent an important benefit to patients and health services provision, reducing the cost of an admission for CABG and increasing the capacity of cardiac surgery units. We conclude that BLPAP could be an important part of an enhanced recovery program for patients undergoing $\mathrm{CABG}$.

The authors thank the patients who participated and the staff in the cardiothoracic unit who made this study possible.

\section{References}

1. Landymore RW, Howell F. Pulmonary complications following myocardial revascularization with the internal mammary artery graft. Eur J Cardiothorac Surg. 1990;4:156-61

2. Tenling A, Hachenberg T, Tyden H, Wegenius G, Hedenstierna G. Atelectasis and gas exchange after cardiac surgery. Anesthesiology. 1998;89:371-8.

3. Magnusson L, Zemgulis V, Wicky S, Tyden H, Hedenstierna G. Effect of CPAP during cardiopulmonary bypass on postoperative lung function. An experimental study. Acta Anaesthesiol Scand. 1998;42:1133-8.

4. Kehlet H, Dahl JB. Anaesthesia, surgery, and challenges in postoperative recovery. Lancet. 2003;362:1921-8.

5. Ram FS, Picot J, Lightowler J, Wedzicha JA. Non-invasive positive pressure ventilation for treatment of respiratory failure due to exacerbations of chronic obstructive pulmonary disease. Cochrane Database Syst Rev. 2004;3:CD004104.
6. Matte P, Jacquet L, Van DM, Goenen M. Effects of conventional physiotherapy, continuous positive airway pressure and non-invasive ventilatory support with bilevel positive airway pressure after coronary artery bypass grafting. Acta Anaesthesiol Scand. 2000;44:75-81.

7. Kosowsky JM, Storrow AB, Carleton SC. Continuous and bilevel positive airway pressure in the treatment of acute cardiogenic pulmonary edema. Am J Emerg Med. 2000;18:91-5.

8. Antonelli M, Conti G, Rocco M, Bufi M, De Blasi RA, Vivino G, et al. A comparison of noninvasive positive-pressure ventilation and conventional mechanical ventilation in patients with acute respiratory failure. $N \mathrm{Engl} \mathrm{J}$ Med. 1998;339:429-35.

9. Lin M, Yang YF, Chiang HT, Chang MS, Chiang BN, Cheitlin MD. Reappraisal of continuous positive airway pressure therapy in acute cardiogenic pulmonary edema. Short-term results and long-term follow-up. Chest. 1995;107:1379-86.

10. Takami Y, Ina H. Beneficial effects of bilevel positive airway pressure after surgery under cardiopulmonary bypass. Interact Cardiovasc Thorac Surg. 2003;2:156-9.

11. Pasquina P, Merlani P, Granier JM, Ricou B. Continuous positive airway pressure versus noninvasive pressure support ventilation to treat atelectasis after cardiac surgery. Anesth Analg. 2004;99:1001-8.

12. Celebi S, Koner O, Menda F, Omay O, Gunay I, Suzer K, et al. Pulmonary effects of noninvasive ventilation combined with the recruitment maneuver after cardiac surgery. Anesth Analg. 2008;107:614-9.

13. Pelosi P, Jaber S. Noninvasive respiratory support in the perioperative period. Curr Opin Anaesthesiol. 2010;23:233-8.

14. Freitas ER, Soares BG, Cardoso JR, Atallah AN. Incentive spirometry for preventing pulmonary complications after coronary artery bypass graft. Cochrane Database Syst Rev. 2007;3:CD004466.

15. Miller MR, Hankinson J, Brusasco V, Burgos F, Casaburi R, Coates A, et al. Standardisation of spirometry. Eur Respir J. 2005;26:319-38.

16. Crowe JM, Bradley CA. The effectiveness of incentive spirometry with physical therapy for high-risk patients after coronary artery bypass surgery. Phys Ther. 1997;77:260-8.

17. Jenkins SC, Soutar SA, Loukota JM, Johnson LC, Moxham J. Physiotherapy after coronary artery surgery: are breathing exercises necessary? Thorax. 1989; 44:634-9.

18. Dwan K, Altman DG, Arnaiz JA, Bloom J, Chan AW, Cronin E, et al. Systematic review of the empirical evidence of study publication bias and outcome reporting bias. PLoS One. 2008;3:e3081.

19. Kirkham JJ, Dwan KM, Altman DG, Gamble C, Dodd S, Smyth R, et al. The impact of outcome reporting bias in randomised controlled trials on a cohort of systematic reviews. BMJ. 2010;340:c365.

20. Calderon J, Richebe P, Guibaud JP, Coiffic A, Branchard O, Asselineau J, et al. Prospective randomized study of early pulmonary evaluation of patients scheduled for aortic valve surgery performed by ministernotomy or total median sternotomy. J Cardiothorac Vasc Anesth. 2009;23:795-801.

21. Moreno AM, Castro RR, Sorares PP, Sant' AM, Cravo SL, Nobrega AC. Longitudinal evaluation the pulmonary function of the pre and postoperative periods in the coronary artery bypass graft surgery of patients treated with a physiotherapy protocol. J Cardiothorac Surg. 2011;6:62.

22. Oikkonen M, Karjalainen K, Kahara V, Kuosa R, Schavikin L. Comparison of incentive spirometry and intermittent positive pressure breathing after coronary artery bypass graft. Chest. 1991;99:60-5.

23. Agostini P, Cieslik H, Rathinam S, Bishay E, Kalkat MS, Rajesh PB, et al. Postoperative pulmonary complications following thoracic surgery: are there any modifiable risk factors? Thorax. 2010;65:815-8.

24. Licker M, Diaper J, Villiger Y, Spiliopoulos A, Licker V, Robert J, et al. Impact of intraoperative lung-protective interventions in patients undergoing lung cancer surgery. Crit Care. 2009;13:R41.

25. Stolz AJ, Lischke R, Schutzner J, Petrik E, Harustiak T, Pafko P. Predisposing factors of atelectasis following pulmonary lobectomy. Acta Chir Belg. 2009; 109:81-5. 